\title{
Sexual function after suburethral sling removal for dyspareunia
}

\author{
Annette Kuhn · Fiona Burkhard · Caroline Eggemann • \\ Michael D. Mueller
}

Received: 5 March 2008/ Accepted: 15 June 2008/Published online: 12 July 2008

(C) Springer Science+Business Media, LLC 2008

\begin{abstract}
Introduction Impact on sexual function has received little attention in the medical literature for a long time. Because of the site of insertion of permanent tension free vaginal tape (TVT) the G spot might be affected or the tape might interfere with arousal and sensory stimulation. Recent studies have reported varying degrees of sexual impairment after TVT insertion ranging from $0 \%$ to $15 \%$ including dyspareunia.

Aim The aim of this study was to evaluate sexual function before and after suburethral sling removal due to postoperative female de novo dyspareunia. As a secondary outcome, general patients' satisfaction with their overall continence situation was assessed.

Patients and methods Between December 2005 and December 2007, we included 18 female patients who complained of de novo dyspareunia after suburethral sling insertion for urinary stress incontinence. All patients filled in an FSFI questionnaire prior to sling removal and at 3 months postoperatively. Additionally, all women were asked to estimate their general satisfaction regarding their continence situation using a Visual Analogue Scale (VAS) from 0 to 10 , with 0 being the least satisfying situation and 10 being the most satisfying situation. All patients underwent gynaecological examination including ICS-pelvic organ prolapse staging (ICS-POP score).
\end{abstract}

\footnotetext{
A. Kuhn $(\varangle) \cdot$ C. Eggemann · M. D. Mueller

Department of Obstetrics and Gynaecology,

Bern University Hospital and University of Bern,

Effingerstr. 102, CH-3010 Bern, Switzerland

e-mail: annette.kuhn@insel.ch

F. Burkhard

Department of Urology, Bern University Hospital and University

of Bern, Bern, Switzerland
}

Results Of the 18 slings, ten were transobturator tapes (6 $\times$ TVT-O, $2 \times$ Monarch, $2 \times$ unknown) and eight were retropubic tapes $(7 \times$ TVT, $1 \times$ SPARC $)$. Desire, arousal, lubrication, satisfaction, and pain improved statistically significant. Orgasm scores were low with median scoring of 1.5 scores before and 1.0 scores after sling removal, and they did not change significantly after sling removal. The satisfaction rate deteriorated from a median of 7 (95\% confidence interval [CI] 6.3-7.7) to a median of 4 (95\% CI $3.7-5.1 ; p=0.99)$ but not statistically significant.

Conclusions Sexual function in patients with de novo dyspareuina is likely to improve after sling removal but not in all domains. Bladder function may deteriorate.

Keywords Gynaecology and obstetrics .

Sexual function - Suburethral slings · Dyspareunia

The insertion of tension-free vaginal tapes was first reported in 1996 for the treatment of female urinary incontinence [1]. A polypropylene tape is placed transvaginally supporting the mid-urethra with no fixation. Inserting a permanent tape below the mid-urethra might affect sexual function and response, particularly if the tape were too tight or were to erode the vagina.

The impact on sexual function has received little attention in the medical literature for long time. The "Gspot" is a supersensitive area for some women on the anterior vaginal wall, the exact site differing among women [2]. Because of the site of insertion of the permanent tension free vaginal tape (TVT) the G spot might be affected or the tape might be felt by the male partner and might interfere with arousal and sensory stimulation. Recent studies have reported varying degrees of sexual 
impairment after TVT insertion ranging from $0 \%$ to $15 \%$, including dyspareunia and loss of libido [3-5].

Occasionally, postoperative dyspareunia due to sling insertion leads to request for sling removal despite the patient being continent and otherwise satisfied.

The Female Sexual Function Index (FSFI) is a brief, self-report measure of female function, which evaluates six different domains of sexual function, including desire, subjective arousal, lubrication, orgasm, satisfaction, and pain. It was first described by Rosen in 2000 [6] and is widely used for the assessment of sexual function.

The aim of this study was to evaluate sexual function before and after suburethral sling removal due to postoperative female de novo dyspareunia. Additionally, patients' general satisfaction with their overall continence situation was assessed.

\section{Patients and methods}

This study was performed in the Department of Gynaecology, Inselspital Bern.

Ethical consent was obtained from the local ethics committee (KEK Bern, registration number 08-10-2007), and patients gave written consent to participate in this study.

Between December 2005 and December 2007, we included all female patients who complained of de novo dyspareunia after suburethral sling insertion for urinary stress incontinence. Exclusion criteria were inability to communicate in one of the local languages or English and/or unwillingness or inability to fill in the FSFI questionnaire.

All patients filled in an FSFI questionnaire prior to sling removal and at 3 months postoperatively. Additionally, all women were asked to estimate their general satisfaction regarding their continence situation using a visual analogue scale (VAS) from 0 to 10 , with 0 being the least satisfying situation and 10 being the most satisfying situation.

All women underwent gynaecological examination including ICS-pelvic organ prolapse staging (ICS-POP Score), urine dipstick, multichannel urodynamics including filling cystometry, pressure-flow studies, urethral profilometry and perineal sonography prior to and 3 months after sling removal and all patients had tried various therapies including local oestrogen treatment, local anaesthetic topical ointment, and pain medications before considering sling removal.

Removal was performed using median colpotomy under regional or general anaesthetic according to the patients' request. The sling was identified and the suburethral part was removed by sharp dissection up to the lateral sulci under careful visual control of the suburethral tissue to avoid urethral injury. Excessive scar tissue was removed and the vaginal epithelium was sutured using Vicryl 2-0 interrupted sutures.

\section{Results}

Eighteen patients could be included in the study. Mean patient age was 53 years (range 32-67) years, median Body Mass Index (BMI) was $28 \mathrm{~kg} / \mathrm{m}^{2}$ (range $24-36 \mathrm{~kg} / \mathrm{m}^{2}$ ), median parity was 2 (range $0-4$ ) and median time interval between original sling insertion and removal was 8 months (range 4-10 months). Median operating time was 15 min (range 10-40 min). Estimated median blood loss was $20 \mathrm{ml}$ (range 10-50 ml).

All patients were sexually active, with 17 in a heterosexual relationship and one in a homosexual relationship.

All of them complained of dyspareunia with an onset after suburethral sling insertion for urodynamic stress incontinence.

There was no tape erosion or poor healing except for one case of a patient with excessive suburethral scar tissue $(5.6 \%)$.

In this woman, additionally to female dyspareunia the male partner suffered from dyspareunia and had injured the penile frenulum at the first attempt of sexual intercourse, resulting in major bleeding. In that case, the sling went through the vagina dividing it into an upper and a lower space like a hammock.

Of the 18 slings, ten were transobturator tapes $(6 \times$ TVT-O, $2 \times$ Monarch, $2 \times$ unknown) and eight were retropubic tapes $(7 \times$ TVT, $1 \times$ SPARC).

In the past, seven patients had had an anterior repair, nine patients a hysterectomy, of whom five had a vaginal hysterectomy, three a laparoscopic hysterectomy, and one an open abdominal hysterectomy for benign reasons. All these patients had had these operations prior to sling insertion. None of the patients had a significant pelvic organ prolapse of more than stage I at the time of sling removal.

Two patients were on systemic hormone-replacement therapy (HRT) and 14 patients were on topical estrogens at the time of sling removal.

In three patients, stress incontinence reoccurred after sling removal.

Figure 1 shows the results of the FSFI questionnaire before and after sling removal. The domain qualities are marked in the same color, with the left column expressing scores before removal and the right column after sling removal.

Desire $(p<0.0001)$, arousal $(p<0.0001)$, lubrication $(p$ $<0.0006)$, satisfaction $(p=0.029)$, and pain $(p<0.0001)$ improved statistically significant.

Orgasm scores were low with median scoring of 1.5 scores before and 1.0 scores after sling removal and did not change significantly after sling removal ( $p=0.82$; all twotailed $t$-test).

Figure 2 shows the patients' satisfaction with their bladder condition expressed by VAS. 


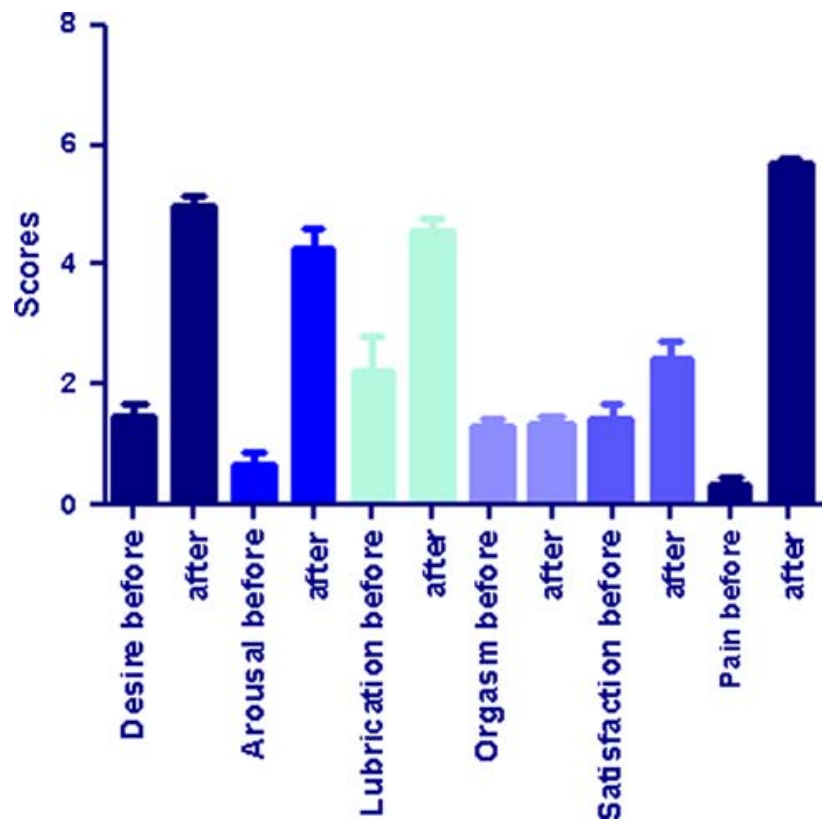

Fig. 1 FSFI domains before and after sling removal

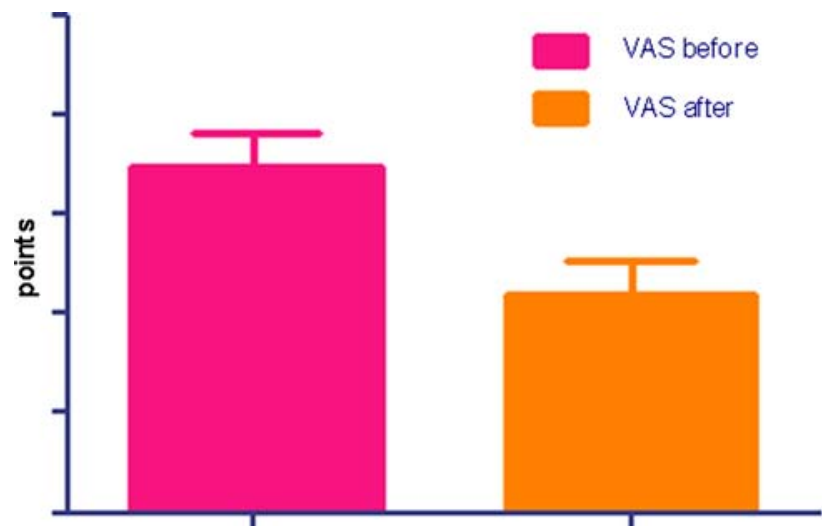

Fig. 2 Patients' satisfaction with their bladder condition before and after sling removal

The satisfaction rate deteriorated from a median of 7 (95\% CI 6.3-7.7) to a median of 4 (95\% CI 3.7-5.1; $p=0.99)$ but not statistically significantly.

\section{Management}

Of the three patients with recurrent stress incontinence, we performed Burch colposuspension in one patient successfully. One patient had a transurethral bladder neck injection as the bladder neck remained immobile after sling removal.

One patient was reluctant to have any further surgery performed and is currently referred to conservative therapy with pessary and pelvic floor exercises.

\section{Discussion}

It is difficult to estimate the percentage of women requiring sling removal based on the current study as $94 \%$ of our patients were referred from other surgeons after the postoperative dyspareunia had arisen. Only one patient was from our clinic; we insert approximately 60 slings per year and have paid attention to sexual function for the past 2 years. Calculations based on these numbers indicate that we have a dyspareunia rate of $1.7 \%$ requiring sling removal; however, as this question was not investigated in this study, this is an estimation only. Karram [7] reports $0.9 \%$ poor healing at the site of the vaginal incision in his study of 350 patients undergoing sling insertion, and $4.9 \%$ voiding dysfunction and $0.5 \%$ of patients requiring another incontinence procedure for recurrent or persisting incontinence.

We cannot be sure why dyspareunia occurred after sling insertion; the literature is contradictory regarding the influence of continence surgery on sexuality.

Impairment of sexual life by urinary incontinence itself has been described without surgery in $30 \%$ of women [8]. Generally, sexual function may be impaired after surgery for stress urinary incontinence. Cayan [9] found that Burch colposuspension deteriorated sexual function much more than vaginal surgery in women, but impact in the vaginal group was evident as well. Shah [10] was unable to show deterioration of sexual function in a series of 29 patients who underwent polypropylene sling insertion for urinary stress incontinence.

The current study shows an improvement of sexual function after suburethral sling removal for dyspareunia in the domains of desire, arousal, lubrication, satisfaction, and particularly pain.

The orgasm domain remained unchanged, with a low scoring prior to intervention. We cannot be sure if this finding is directly related to sling insertion as patients had additional gynaecologic surgery in the past: $50 \%$ had had hysterectomy for benign reasons and 35\% an anterior colporrhaphy.

Reports on the impact of hysterectomy on sexual function have been conflicting, with some evidence of improvement after hysterectomy [11, 12] but also of sexual impairment [13].

Similarly, some investigators have reported that the surgical management of pelvic organ prolapse improves sexual function in the patients [14]. However, this positive effect of treatment has not been confirmed by all researchers $[15,16]$. A pre-existing alteration of sexual function due to anterior repair is possible. Anterior repair may cause scarring of the anterior vaginal wall and suburethral area and may contribute to a loss of physiological 
sexuality. We have no information on sexual function prior to sling insertion, which is a weakness of the study.

One strength of this study is its prospective design and the use of validated tools. In this study, we used the translated standardized FSFI questionnaire, which is designed according to the three-phase model of female sexual response described by Kaplan [6]. Unfortunately, a translated validated version of FSFI was not available at the time of the study.

Recurrence of stress incontinence is a known risk after sling removal [17]. In our study, $15 \%$ of patients experienced recurrence of stress incontinence, which is probably the reason why patients' overall satisfaction with their bladder condition dropped by three points using the VAS, which is a validated tool to assess patients' perception [15-17].

Considering the route of sling insertion, there is some evidence that transobturator tapes cause more dyspareunia than classical retropubic tapes with $7-10 \%$ for the transobturator route $[18,19]$ and $1-3.3 \%$ for retropubic tapes [20, 21]. In our study, both surgical routes were almost equally represented, with ten transobturator tapes and eight retropubic slings. Randomized trials with sufficient power to determine which route is best regarding sexual function are missing. It is advisable to inform the patient before any sling insertion that dyspareunia may occur.

As for the male injury, there is no Medline literature to compare with. Male dyspareunia may be due to anatomical reasons such as balanitis or a short frenulum $[22,23]$ but we did not examine the male partner of our patient. However, with the sling being placed through the midvaginal opening it is indeed unlikely to be caused by the male anatomy but by the wrongly placed sling.

In conclusion, if de novo dyspareunia after sling insertion occurs and conservative therapy including topical oestrogen application, lubricants, and sometimes even pain medication fails, suburethral sling removal needs to be discussed. We can reassure the patient that sexual function is likely to improve but not in all domains.

\section{References}

1. Ulmsten U, Henriksson L, Johnson P, Varhos G (1996) An ambulatory surgical procedure under local anaesthesia for treatment of female urinary incontinence. Int Urogynaecol J 7:81-86

2. Hines TM (2001) The G-Spot: a modern gynaecologic myth. Am J Obstet Gynecol 185:359-362

3. Mazouni C, Karsenty G, Bretelle F, Bladou F, Gamerre M, Serment G (2004) Urinary complications after sexual function after the tension-free vaginal tape procedure. Acta Obstet Gynecol Scand 83:955-961

4. Maaita M, Bhaumik J, Davies AE (2002) Sexual function after tension-free vaginal tape for the surgical treatment of genuine stress incontinence. BJU Int 90:540-543
5. Ghezzi F, Serati M, Cromi A, Uccella Striacca P, Bolis P (2005) Impact of tension-free vaginal tape on sexual function: results of a prospective study. Int Urogynecol J 17:54-59

6. Rosen R, Brown C, Heiman J, Leiblum S, Meston C, Shabsigh R, Ferguson D, D'Agostino R Jr (2000) The Female Sexual Function Index (FSFI): a multidimensional self-report instrument for the assessment of female sexual function. J Sex Marital Ther 26(2):191-208

7. Karram MM, Segal JS, Vassallo BJ, Kleeman SD (2003) Complications and untoward effects on the tension-free vaginal tape procedure. Obstet Gynecol 929-993

8. Trammel C, Humdinger G, Schmidbauer J, Schatzl G, Madersbacher S (2000) Urinary incontinence in both sexes: prevalence rates and impact on quality of life and sexual life. Neurourol Urodyn 19:259-271

9. Cayan F, Dilck S, Akbay E, Cayan S (2008) Sexual functioning after surgery for stress urinary incontinence: vaginal sling versus Burch colposuspension. Arch Gynecol Obstet 277:31-36

10. Shah SM, Bukkapatnam R, Rodriguez LV (2005) Impact of vaginal surgery for stress urinary incontinence on female sexual function: is the use of polypropylene mesh detrimental? Urology 65:270-274

11. Mokate T, Wright C, Mander T (2006) Hysterectomy and sexual function. J Br Menopause Soc 12(4):153-157

12. Ghielmetti T, Kuhn P, Dreher EF, Kuhn A (2006) Gynaecological operations: do they improve sexual life? Eur J Obstet Gynecol Reprod Biol 129(2):104-110

13. Raina R, Pahlani G, Khan S, Gupta S, Agarwal A (2007) Zippe CD Female sexual dysfunction: classification, pathophysiology and management. Fertil Steril 88(5):1273-1284

14. Weber AM, Walters MD, Piedmonte MR (2000) Sexual function and vaginal anatomy in women before and after surgery for pelvic organ prolapse and urinary incontinence. Am J Obstet Gynecol 182(6):1610-1615

15. Francis WJ, Jeffcoate TNA (1961) Dyspareunia following vaginal operations. J Obstet Gynaecol Br Commonwealth 68:1-10

16. Haase P, Skibsted L (1988) Influence of operations for stress incontinence and 7 or genital descensus on sexual life. Acta Obstet Gynecol Scand 67(7):659-661

17. Haesakkers JP, Vierhout ME (2007) Some complications of tension-free midurethral tapes for the treatment of stress incontinence in women. Ned Tijdschr Geneeskd 151(24):1361-1366

18. Giberti C, Galoo F, Cortese P, Schenone M (2007) Transobturator tape for the treatment of female stress urinary incontinence: objective and subjective results after a mean follow-up of two years. Urology 69(4):703-707

19. Kuschel S, Schuessler B (2007) Results on function and safety of the Safyre-t, a hybrid transobturator vaginal sling for the treatment of stress urinary incontinence Neurourol Urodyn; Epub ahead of print

20. Ismail SI (2007) Audit of compliance with NICE guidelines on the use of tension-free vaginal tape slings for stress urinary incontinence. J Obstet Gynaecol 27(5):496-499

21. Abdel-Fattah M, Barrington JW, Arunkalaivanam AS (2004) Pelvicol pubovaginal sling versus tension-free vaginal tape for treatment of urodynamic stress incontinence: a prospective randomized three-year follow-up study. Eur Urol 46(5):629-635

22. Shechet J, Tannenbaum B, Fried SM (1999) Male dyspareunia in the uncircumcised patient. Am Fam Physician 60(1):54, 56

23. Whelan $P$ (1977) Male dyspareunia due to short frenulum: an indication for adult circumcision. Br Med J 2(6103):1633-1634 